\title{
LA PROTECCIÓN JURÍDICA DEL NASCITURUS EN EL ORDENAMIENTO JURÍDICO ESPAÑOL
}

\author{
$\mathbf{M}^{\mathrm{a}}$ del Carmen Cazorla González-Serrano \\ Profesora Titular (I.) Derecho Civil URJC
}

\begin{abstract}
RESÚMEN: El objetivo en las presentes líneas se centra en el aspecto jurídico positivo, concretamente en lo que se refiere a la protección que el Ordenamiento Jurídico español concede al nasciturus en dos planos; uno, que se encarga de reconocer su status y derechos como nasciturus y, en segundo término, el plano sancionador o represivo que abarca las distintas sanciones para con las conductas que, de algún modo, transgreden el reconocimiento y la protección jurídica dispensada al mismo. Nos hallamos ante una de las cuestiones que, sin lugar a dudas, ha provocado uno de los debates sociales de nuestro tiempo.
\end{abstract}

PALABRAS CLAVE: Nasciturus, protección jurídica, daños prenatales, sanción.

\begin{abstract}
The objective in the present lines focuses on the positive legal aspect, specifically regarding the protection that the Spanish Legal Order grants to the nasciturus in two planes; one, which is responsible for recognizing their status and rights as nasciturus and, secondly, the sanctioning or repressive plan that includes the various sanctions for conduct that, in some way, transgress the recognition and legal protection provided to it. We are faced with one of the issues that, undoubtedly, has provoked one of the social debates of our time.
\end{abstract}

KEY WORDS: Nasciturus, legal protection, prenatal damages, sanction. 
SUMARIO: I. Consideraciones generales. II. El artículo 29 como norma jurídica de reconocimiento de protección general del nasciturus. III. La protección jurídica del nasciturus en los ámbitos penal, administrativo, procesal, sanitario y civil. IV. La protección de la vida e integridad física del nasciturus: STC 53/1985, de 11 de abril, sobre el aborto.

\section{Consideraciones generales}

En nuestro ordenamiento jurídico, a partir del último tercio del siglo XX, se ha producido una actividad legislativa dirigida a proporcionar una mayor protección jurídica a los menores de edad $^{1}$. Por el contrario, esta preocupación por atender las necesidades de dichos menores no se ha producido con la misma intensidad a la hora de proporcionar protección a los concebidos no nacidos o nasciturus, lo cual no significa que estos carezcan en nuestro derecho de cierta protección, pero no alcanza a la proporcionada a los menores nacidos.

En España, a partir de la publicación de la Constitución Española de 1978, se ha prestado especial atención a la situación jurídica de los menores de edad en nuestro país tanto a nivel estatal como a nivel autonómico. Fruto de ello ha sido la publicación de la Ley Orgánica 1/1996, de 15 de enero, de Protección Jurídica del Menor, de modificación del Código Civil y de la Ley de Enjuiciamiento Civil, que tanta incidencia ha tenido en España en el reconocimiento de los derechos y protección de los menores de edad, y que fue secundada por diversas leyes sobre la infancia y la juventud publicadas por las distintas Comunidades Autónomas. Esta norma ha sido recientemente reformada por la Ley Orgánica 8/2015, de 22 de julio, de modificación del sistema de protección a la infancia y la adolescencia y por la Ley 26/2015, de 28 de julio de protección a la infancia y a la adolescencia, en la que, por primera vez en unas Leyes de esta envergadura, se contempla la protección del concebido no nacido al considerar la posible situación de riesgo prenatal. Sin embargo, frente a la abundante y detallada legislación respecto a los derechos de los menores nacidos, llama la atención la escasa regulación entorno a los derechos y protección jurídica del nasciturus.

\footnotetext{
${ }^{1}$ Véase, entre otros, la Declaración de Ginebra, aprobada por unanimidad, en la Sociedad de Naciones en 1924, la Declaración de los Derechos del Niño, aprobada por la Asamblea General de Naciones Unidas el 20 de noviembre de 1959, y la Convención sobre los Derechos del Niño, aprobada por la Asamblea General de las Naciones Unidas el 20 de noviembre de 1989, ratificada por España el 21 de diciembre de 1990 (BOE 31 de diciembre 1990, núm. 313) y que entró en vigor el 5 de enero de 1991.
} 
Diversas teorías doctrinales han tratado de determinar la naturaleza jurídica de la protección pero la doctrina mayoritaria sigue la "teoría de la situación de pendencia", ${ }^{2}$ esto es, al concebido no se le concede personalidad jurídica (aptitud para ser titular de derechos y obligaciones), en cuanto que la misma se adquiere por el nacimiento. Durante esta situación de pendencia y hasta que se produzca el nacimiento, se le tiene por nacido para todos los efectos que le sean favorables., es decir, todo aquello que comporte una adquisición de derechos, aunque ineludiblemente dicho derecho pueda conllevar una carga o gravamen.

\section{El artículo 29 como norma jurídica de reconocimiento de protección general del nasciturus}

En nuestro ordenamiento jurídico el concebido no nacido no tiene consideración de persona. Efectivamente, el artículo 29 del Código Civil establece: "El nacimiento determina la personalidad, pero el concebido se tiene por nacido para todos los efectos que le sean favorables, siempre que nazca con las condiciones que expresa el artículo siguiente". El artículo 30, dispone: "La personalidad se adquiere en el momento del nacimiento con vida, una vez producido el entero desprendimiento del seno materno". La atribución de personalidad jurídica supone el reconocimiento de una persona como sujeto de derechos y obligaciones. Y en nuestro derecho, como se acaba de indicar, la personalidad jurídica se adquiere por el nacimiento, siempre que se cumplan los dos requisitos exigidos en el artículo 30, esto es, nacer con vida y el entero desprendimiento del seno materno.

La calificación del nasciturus como persona ha dado lugar a una importante polémica, tanto doctrinal como social, pues, a pesar de lo que se deduce del citado artículo 29 y de la doctrina del Tribunal Constitucional ${ }^{3}$, hay una corriente doctrinal que estima que el nasciturus es persona desde el mismo momento de su concepción y como tal es sujeto de derechos desde ese mismo instante ${ }^{4}$. Sin embargo, la doctrina mayoritaria, en base a los citados preceptos 29

\footnotetext{
${ }^{2}$ DE LA IGLESIA MONJE, I.: "La protección del nasciturus y su proyección en la jurisprudencia civil actual", en RCDI, no 726, pp. 2218 y 2219.

${ }^{3}$ En la conocida STC 53/1985, de 11 de abril, se examinó la constitucionalidad del artículo 417 bis del Código penal en el que se despenalizaban determinados supuestos de aborto, considerado como delito en aquellos momentos históricos, en cuyo Fundamento Jurídico 5 afirma expresamente que el nasciturus no es titular del Derecho fundamental a la vida.

${ }^{4}$ En este sentido, CALVO MEJIDE, A. ("El nasciturus como sujeto del derecho. Concepto constitucional de persona frente al concepto pandectista-civilista", en Cuadernos de Bioética, 2004 (2), pp. 91-93) señala expresamente que "El nasciturus es, pues, persona desde las fases embrionaria y fetal, realidad que debería ser reconocida por el Derecho Positivo, superando una concepción decimonónica de la persona y acogiendo con mayor amplitud el concepto jurídico-constitucional derivado del artículo 10 de la Constitución Española, y, en su consecuencia, reconociéndole como sujeto titular de los derechos que son inherentes a todo ser humano"; MARTÍNEZ DE AGUIRRE Y ALDAZ, C. ("Comentarios a los artículos 29 a 34 del Código Civil", en Comentarios al Código Civil, t. II, vol. $1^{\circ}$, coord. por J. Rams Albesa, ed. Bosch, Barcelona, 2000, pp. 256 y 257) defiende la consideración como persona del ser humano desde el mismo momento de la concepción, de
} 
y 30 del Código Civil, considera que el concebido no nacido no tiene personalidad jurídica hasta el momento de su nacimiento con vida y su entero desprendimiento del seno materno; es pues, en este momento, cuando se le viene reconocido como titular de derechos ${ }^{5}$.

Pese a lo manifestado, nuestro ordenamiento jurídico dota al concebido no nacido de una particular protección. La Sentencia del Tribunal Constitucional 53/1985, después de hacer algunas consideraciones generales sobre el derecho a la vida, concluye que "la vida del nasciturus, en cuanto éste encarna un valor fundamental -la vida humana- garantizado en el artículo 15 de la Constitución, constituye un bien jurídico cuya protección encuentra en dicho precepto fundamento constitucional". Asimismo, el propio Tribunal señala que "esta protección que la Constitución dispensa al nasciturus implica para el Estado con carácter general dos obligaciones: la de abstenerse de interrumpir o de obstaculizar el proceso natural de gestación, y la de establecer un sistema legal para la defensa de la vida que suponga una protección efectiva de la misma y que, dado el carácter fundamental de la vida, incluya también, como última garantía, las normas penales", aunque advierte que dicha protección no significa que haya de revestir carácter absoluto, pues, en determinados supuestos puede y debe estar sujeta a limitaciones.

El punto crucial del artículo 29 del Código civil radica en reconocer el alcance de la expresión que utiliza el legislador "para todos los efectos que sean favorables" ya que implica la exclusión de los efectos perjudiciales y la facultad general de adquirir derechos aunque puedan pesar cargas y gravámenes sobre los mismos. En el Código civil cuando se mencionan derechos a favor de los concebidos éstos son de carácter patrimonial, inter vivos o mortis causa, y se le atribuyen siempre que se produzca su nacimiento. Por lo que más que la atribución de una titularidad se está produciendo una reserva de la titularidad de estos derechos. Concretamente en el Código Civil se reconoce la posibilidad de realizar donaciones a los concebidos no nacidos (art. 627 C.c.), y de nombrarles herederos. Sin embargo, la doctrina amplia el contenido de los efectos, señalando que éstos no se limitan únicamente a la esfera patrimonial sino también a los de carácter personal o extrapatrimonial ${ }^{6}$. Así, en virtud del artículo 29.2 del Código civil la doctrina estudia las posibles indemnizaciones derivadas

modo que antes de su nacimiento su personalidad es restringida y está limitada a la titularidad de los derechos naturales primarios (la vida, la integridad física, etc.).

${ }^{5}$ Niegan la consideración de persona al concebido no nacido, entre otros, DÍEZ PICAZO, L.: “Comentario al artículo 30 del Código Civil” en Comentarios al Código Civil y Compilaciones Forales, dirig. por M. Albaladejo, t. I, Edersa, Madrid, 1978, p. 811; y LACRUZ BERDEJO, J.L., SANCHO REBULLIDA, F. de A., SERRANO, A., DELGADO ECHEVARRÍA, J., RIVERO HERNÁNDEZ, F., RAMS ALBESA, J.: Elementos de Derecho Civil I, vol. $2^{\circ}$, Personas, $3^{\text {a }}$ ed. Revisada y puesta al día por J. Delgado, Dykinson, Madrid, 2002, p. 15.

${ }^{6}$ LALAGUNA DOMÍNGUEZ, E.: "El artículo 29 del Código Civil como norma general de protección jurídica del concebido", en RJN, n 39, 2001, pp. 141 y 142; y GONZÁLEZ GOZALO, A.: "Comentario al artículo 30 del Código Civil”, en Comentarios al Código Civil, coord. por R. Bercovitz Rodríguez-Cano, Thomson Aranzadi, $3^{\text {a }}$ ed., 2009, p. 144. 
de la responsabilidad civil por actos que hayan ocasionado daños al nasciturus ${ }^{7}$. En este sentido, se admite que cabe la atribución de una indemnización de la responsabilidad procedente de la ejecución de cualquier tipo de hecho dañoso y que tal indemnización comprende los daños materiales como los personales. De este modo, el nacido puede reclamar por derecho propio el resarcimiento de los daños, morales y patrimoniales, con efectos retroactivos, ocasionados durante la gestación ${ }^{8}$.

\section{Protección jurídica del nasciturus en los ámbitos penal, administrativo, procesal, sanitario y civil}

Durante la gestación, la vida y la salud del nasciturus puede ser menoscabada bien por causas espontáneas, sin intervención de terceros, bien por la intervención de terceros (parientes, profesionales sanitarios o los mismos progenitores que, sin ánimo de causar estos daños de forma intencionada, intervienen en el desarrollo normal del concebido no nacido). Nuestro ordenamiento jurídico prevé diversos instrumentos que permiten proteger al nasciturus por los daños sufridos.

El concebido no nacido viene protegido por nuestro ordenamiento jurídico de los daños derivados de determinados delitos. Por un lado, en el ámbito penal, se encuentra la protección que el Código dispensa al concebido a través del delito de aborto en los artículos 144 a 146 y más concretamente por el tema que nos atañe, a través del delito de lesiones al feto de los artículos $157^{9}$ y $158^{10}$. A ello hay que añadir que el propio Código penal, en el ámbito de la investigación biomédica y de la reproducción humana asistida, y en defensa de los preembriones y embriones, establece los delitos de manipulación genética en los artículos 159a $162^{11}$.

\footnotetext{
${ }^{7}$ En este sentido, se manifiestan, entre otros, DE CASTRO Y BRAVO, F.: Derecho civil de España, t. II, Civitas, Madrid, 1984, p.31; y GONZÁLEZ GONZALO, A.: ob. cit., p. 144.

${ }^{8}$ Sobre este particular, en LACRUZ BERDEJO, J.L., SANCHO REBULLIDA, F. de A., SERRANO, A., DELGADO ECHEVARRÍA, J., RIVERO HERNÁNDEZ, F., RAMS ALBESA, J. (ob. cit. p. 17) se señala que "la retroacción de la personalidad puede ayudar al nacido en la reclamación, por derecho propio, del resarcimiento por lesiones que se le causaron estando en el claustro materno y cuyos efectos persistan luego".

${ }^{9}$ Art. 155 C.c.: "El que, por cualquier medio o procedimiento, causare en un feto una lesión o enfermedad que perjudique gravemente su normal desarrollo, o provoque en el mismo una grave tara física o psíquica, será castigado con pena de prisión de uno a cuatro años e inhabilitación especial para ejercer cualquier profesión sanitaria, o para prestar servicios de toda índole en clínicas, establecimientos o consultorios ginecológicos, públicos o privados, por tiempo de dos a ocho años".

${ }^{10}$ Art. 158 C.c.: "El que, por imprudencia grave, cometiere los hechos descrito en al artículo anterior, será castigado con la pena de prisión de 3 a cinco meses o multa de seis a diez meses.

Cuando los hechos descritos en el artículo anterior fueren cometidos por imprudencia profesional se impondrá a sí mismo la pena de inhabilitación especial para el ejercicio d la profesión, oficio o cargo por un periodo de seis meses a dos años".

${ }^{11}$ Art. 159 C.c.: "Serán castigados con la pena de prisión de dos a seis años e inhabilitación especial para empleo o cargo público, profesión u oficio de siete a diez años los que, con finalidad distinta a la eliminación o disminución de taras o enfermedades graves, manipulen genes humanos de manera que se altere el genotipo.
} 
Por su parte, en el ámbito jurídico-administrativo, la protección del concebido no nacido, como las sanciones que se puedan imponer en este ámbito se recogen en la Ley 30/1992, de 26 de noviembre, de Régimen Jurídico de las Administraciones Públicas y del Procedimiento Administrativo Común y en la Ley 14/1986, de 25 de abril, General de Sanidad. Estas normativas regulan las técnicas de reproducción humana asistida y la investigación biomédica y su correspondiente actividad sancionadora. La potestad sancionadora regulada en estas leyes, se ejercerá en lo no previsto en las mismas por la Ley 14/2006, de 26 de mayo (arts. 24 a 28) y Ley 14/2007, de 3 de julio, de Investigación Biomédica (arts. 72 a 75). En ambos textos el Legislador establece una serie de conductas sancionables, procediendo a una clasificación de las mismas en tres categorías: leves, graves y muy graves.

Cuando a juicio de la Administración, la infracción pudiera ser constitutiva de delito o falta, el órgano administrativo dará traslado al Ministerio Fiscal y se abstendrá de proseguir el procedimiento sancionador mientras la autoridad judicial no se haya pronunciado. Igualmente, la sanción penal excluirá la imposición de sanción administrativa, y de no haberse estimado la existencia de delito, la Administración continuará el expediente sancionador tomando como base los hechos que los Tribunales hayan considerado probados.

2. Si la alteración del genotipo fuere realizada por imprudencia grave, la pena será de multa de seis a quince meses e inhabilitación especial para empleo o cargo público, profesión u oficio de uno a tres años".

Art. 160 C.c.: "1. La utilización de la ingeniería genética para producir armas biológicas o exterminadoras de la especie humana, será castigada con la pena de prisión de tres a siete años e inhabilitación especial para empleo o cargo público, profesión u oficio por tiempo de siete a 10 años.

2. Serán castigados con la pena de prisión de uno a cinco años e inhabilitación especial para empleo o cargo público, profesión u oficio de seis a 10 años quienes fecunden óvulos humanos con cualquier fin distinto a la procreación humana.

3. Con la misma pena se castigará la creación de seres humanos idénticos por clonación u otros procedimientos dirigidos a la selección de la raza".

Art. 161 C.c.: "1. Quien practicare reproducción asistida en una mujer, sin su consentimiento, será castigado con la pena de prisión de dos a seis años, e inhabilitación especial para empleo o cargo público, profesión u oficio por tiempo de uno a cuatro años.

2. Para proceder por este delito será precisa denuncia de la persona agraviada o de su representante legal. Cuando aquélla sea menor de edad, persona con discapacidad necesitada de especial protección o una persona desvalida, también podrá denunciar el Ministerio Fiscal".

Art. 162 C.c.: "En los delitos contemplados en este título, la autoridad judicial podrá imponer alguna o algunas de las consecuencias previstas en el artículo 129 de este Código cuando el culpable perteneciere a una sociedad, organización o asociación, incluso de carácter transitorio, que se dedicare a la realización de tales actividades". 
En el ámbito procesal se permite al concebido no nacido que sea parte en los procesos judiciales en aquella materia que les afecte. Concretamente, en el artículo 6.1, $2^{\circ}$ de la LEC, se establece que podrán ser parte en los procesos ante los tribunales civiles: " $2 .{ }^{\circ}$ el concebido no nacido, para todos los efectos que le sean favorables", en el que, como se observa, se hace una remisión implícita al artículo 29, segundo inciso, del Código civil. Ante su imposibilidad de comparecer el artículo 7.3 de la LEC establece que: "Por los concebidos y no nacidos comparecerán las personas que legítimamente les representarían si ya hubieren nacido". La inclusión en la LEC de la capacidad procesal del concebido no nacido supone la expresión de la auténtica protección civil del mismo.

En el ámbito sanitario, también se deriva una responsabilidad de carácter específico, por las actuaciones de los profesionales sanitarios que causen daños o lesiones al concebido no nacido. Además de los supuestos previstos en los casos de aborto y de lesiones al feto en el Derecho español se han ido admitiendo las denominadas acciones "wrongful birth" y "wrongful life", que se producen sobre la base de una demanda que solicita el resarcimiento de los daños producidos por el nacimiento de un niño con malformaciones o enfermedades congénitas debido a la negligencia omisiva del facultativo responsable. Esta demanda puede interponerse por los progenitores del nacido o por uno de ellos (acciones wrongful birth), o bien por el propio nacido, a través de sus representantes legales (acciones wrongful life) ${ }^{12}$.

Por último, en el ámbito civil nuestro Código establece la responsabilidad civil extracontractual por los daños de carácter material o moral, realizados a terceros, en cuanto el artículo 1902 establece que: "El que por acción u omisión causa daño a otro, interviniendo culpa o negligencia está obligado a reparar el daño causado".

\section{La protección de la vida e integridad física del nasciturus: STC 53/1985, de 11 de abril, sobre el aborto.}

A diferencia de lo que ocurre con las actuaciones negligentes ocasionadas por terceros al concebido no nacido que expresamente encuentran su regulación en nuestro Ordenamiento Jurídico, no existe una norma que de manera explícita regule las consecuencias de una actuación dañosa para el concebido no nacido por parte de los progenitores a través de la transmisión de enfermedades o malformaciones. Ello no quiere decir que tales acciones que menoscaban la salud del nasciturus queden exentas de responsabilidad.

\footnotetext{
${ }^{12}$ Vide MACÍA MORILLO, A.: "La responsabilidad civil médica. La llamadas acciones de wrongful birth y wrongful life", Revista de Derecho, Universidad del Norte, 2007 (27), p. 20.
} 
Sobre este particular, el Tribunal Constitucional en la citada Sentencia 53/1985 se postula reconociendo el deber de proteger la vida $\mathrm{y}$, consecuentemente, la integridad física del concebido. Al analizar el alcance del artículo 15 de la Constitución Española en cuanto a la titularidad del derecho en el garantizado, consideró que la vida "es un concepto indeterminado sobre el que se han dado respuestas plurívocas no sólo en razón de las distintas perspectivas (genética, médica, teológica, etc.), sino también en virtud de los diversos criterios mantenidos por los especialistas dentro de cada uno de los puntos de vista considerados", y partía de una noción básica de la vida precisando que "la vida humana es un devenir, un proceso que comienza con la gestación, en el curso de la cual una realidad biológica va tomando corpórea y sensitivamente configuración humana, y que termina en la muerte; es un continuo sometido por efectos del tiempo a cambios cualitativos de naturaleza somática y psíquica que tienen un reflejo en el status jurídico público y privado del sujeto vital", señalando que la gestación ha generado un tertium existencialmente distinto de la madre, aunque alojado en el seno de ésta, y que "dentro de los cambios cualitativos en el desarrollo del proceso vital y partiendo del supuesto de que la vida es una realidad desde el inicio de la gestación, tiene particular relevancia el nacimiento, ya que significa el paso de la vida albergada en el seno materno a la vida albergada en la sociedad, bien que con distintas especificaciones y modalidades a lo largo del curso vital". Y finalizaba considerando que "previamente al nacimiento tiene especial trascendencia el momento a partir del cual el nasciturus es ya susceptible de vida independiente de la madre, esto es, de adquirir plena individualidad humana".

A la vista de todo ello, el Tribunal Constitucional concluye que si la Constitución protege la vida con tanta relevancia, "no puede desprotegerla en aquella etapa de su proceso que no sólo es condición para la vida independiente del claustro materno, sino que es también un momento del desarrollo de la vida misma"; por lo que la vida del nasciturus, en cuanto éste encarna un valor fundamental (la vida humana) garantizado en el artículo 15 de la Constitución, "constituye un bien jurídico cuya protección encuentra en dicho precepto fundamento constitucional".

Las conclusiones del Tribunal Constitucional conllevan que tanto la vida del concebido como su integridad física se encuentran protegidas constitucionalmente, aunque éste no sea titular de los derechos a la vida y a la integridad física y moral reconocidos en el artículo 15.

En particular, dicha protección se realiza en las normas anteriormente citadas en el Código penal y en las leyes sobre investigación biomédica y aplicación de las técnicas de reproducción humana asistida, a las que hay que añadir la referencia que la Ley 26/2005, de 28 de julio, de modificación del sistema de protección a la infancia y a la adolescencia a las 
situaciones de riesgo prenatal. Sin embargo, en las leyes de reproducción humana asistida y de investigación biomédica se distinguen varias situaciones en las que se puede encontrar el concebido no nacido, según las distintas fases por la que pasa su desarrollo desde el momento de la fecundación hasta el momento del parto. Teniendo en cuenta dichas fases, en nuestra legislación se diferencia entre preembrión, embrión y feto.

La consecuencia de dicha distinción produce una diferente protección del concebido, dado que, según la fase de desarrollo en que éste se encuentre, nuestra legislación permite la intervención sobre el preembrión y el embrión, tanto a efectos de una fecundación artificial como a efectos de una investigación científica. Por tanto, esta permisibilidad limita la protección del concebido ${ }^{13}$ ya que como apunta el Tribunal Constitucional en su sentencia 53/1985, la protección de la vida del nasciturus no significa que haya de revestir carácter absoluto pues en determinados supuestos debe estar sujeta a limitaciones.

Las enfermedades que los progenitores pueden transmitir a sus hijos concebidos y que pueden menoscabar la salud de los mismos pueden transmitirse durante la gestación (anomalías cromosomáticas, defectos de un único gen, problemas multifactoriales, trastornos mitocondriales ligados al ADN, problemas teratogénicos, enfermedad transmisible o secuela ocasionada al neonato durante el parto y enfermedad transmisible durante la lactancia $)^{14} \mathrm{o}$ bien, tratarse de enfermedades heredables o enfermedades genéticas que pueden dividirse en tres:

a) Enfermedades (o rasgos) nomogénicas, con herencia mendeliana más o menos regular. Por ejemplo: la hemofilia, la talasemia y la acondroplasia, entre otras.

b) Enfermedades (o rasgos) de herencia multifactorial, con frecuencia poligénicas y a veces nomogénicas, con un componente ambiental significativo. Por ejemplo: el paladar hendido.

c) Enfermedades de origen cromosómico, no heredables.

Es esta pues, una materia extraordinariamente delicada por cuanto nos encontramos en el círculo más íntimo de las personas y las relaciones familiares más profundas. La admisión de la posibilidad de permitir la interposición de una demanda a los hijos contra sus propios

\footnotetext{
${ }^{13}$ FEMENÍA LÓPEZ, P. (“Embrión (jurídico)”, Enciclopedia de Bioderecho y Bioética, t. I (Director Carlos María Romero Casabona), Cátedra Interuniversitaria, Fundación BBVA-Diputación Foral de Vizcaya, Universidad de Deusto, ed. Comares, Granada, 2011, pp. 705 y 711) señala que no puede otorgarse al embrión el mismo grado de protección jurídica que al individuo ya nacido, pues la gestación es un proceso biológico sometido a cambios cualitativos, que se inicia con la fecundación y termina con el nacimiento, "por lo que se encuentra perfectamente justificada una intensificación de la protección jurídica a medida que se adquiera mayor certidumbre en la conclusión del proceso".

${ }^{14}$ Esta clasificación se realiza en la Enciclopedia Médica MedlinePlus, sitio web de los Institutos Nacionales de la Salud para pacientes, familiares y amigos, producida por la Biblioteca Nacional de medicina de los Estados Unidos: https://www.nlm.nih.gov/medlineplus/spanish/aboutmedlineplus.html.
} 
progenitores para resarcirse de los daños efectuados a aquel en el momento de la procreación o durante la gestación del mismo, parece que implica la ruptura de los lazos familiares.

Debido a ello, podría decirse que falta un consenso doctrinal sobre la cuestión, aunque hay un punto coincidente: que esta cuestión constituye actualmente un problema emergente, tanto jurídico como bioético y social, aún no resuelto. 
